\title{
AKUPRESSURE PADA TITIK HEGU UNTUK MENGATASI NYERI MENSTRUASI
}

\author{
Accupresure on Hegu Point to Treat Menstrual Pain \\ Gita Kostania ${ }^{1}$, Kuswati ${ }^{2}$, Ati Fitriyani ${ }^{3}$ \\ Jurusan Kebidanan, Poltekkes Kemenkes Surakarta \\ (kostania.gita@gmail.com)
}

\begin{abstract}
ABSTRAK
Latar Belakang : Menstruasi merupakan tanda pubertas seorang wanita dan menjadi rutinitas wanita yang masih dalam masa subur. Siklus ini menimbulkan ketidaknyamanan, salah satunya nyeri menstruasi. Nyeri ini dapat berupa kram ringan hingga dapat mengganggu kegiatan sehari-hari. Nyeri menstruasi dapat dikurangi secara farmakologis dan non farmakologis. Secara non farmakologis salah satunya adalah dengan akupresure pada titik Hegu.

Tujuan : Penelitian ini bertujuan untuk mengetahui pengaruh akupresure titik hegu terhadap nyeri menstruasi.

Metode : Penelitian ini merupakan penelitian observasional. Jenis penelitian quasy eksperiment dengan rancangan non equivalent control group. Populasi aktualnya yaitu santriwati kelas XI Madrasah Bertaraf Internasional Amanatul Ummah Mojokerto yang mengalami nyeri menstruasi sebanyak 126 orang. Teknik pengambilan sample adalah purposive sampling dengan perhitungan rumus Slovin, didapatkan sebanyak 56 responden. Instrumen penelitian menggunakan lembar observasi dengan pengukuran Numeric Rating Scale. Analisis data menggunakan independent t-test.

Hasil : Hasil penelitian menunjukkan bahwa terdapat perbedaan penurunan nyeri menstruasi antara kelompok eksperimen dan kelompok kontrol dengan $\mathrm{p}=0,001$ $(\mathrm{p}<0,05)$. Rata - rata penurunan tingkat nyeri mesntruasi pada kelompok eksperimen sebesar 3,79 dan kelompok kontrol sebesar 2,00. Hal ini menyatakan bahwa akupresure pada titik hegu dapat mengurangi nyeri menstruasi pada santriwati kelas XI Madrasah Bertaraf Internasional Amanatul Ummah Mojokerto
\end{abstract}

Simpulan : Akupresure pada titik Hegu dapat dilakukan untuk mengurangi nyeri menstruasi.

Kata kunci : Akupresure, titik Hegu, nyeri menstruasi.

\begin{abstract}
Background: Menstruation is a sign of puberty in a woman and becomes a routine for women who are still in their fertile period. This cycle causes discomfort, one of which is menstrual pain. This pain can be mild cramps, so it can interfere with daily activities. Menstrual pain can be reduced by
\end{abstract}


pharmacologically and non-pharmacologically. One of the non-pharmacological methods is acupressure at the Hegu point.

Objective: This study aimed to study the effect of the Hegu point towards menstrual pain.

Method: This study is an observational study. This type of research is quasy experiment with a non equivalent control group design. The actual population is students of class XI "Madrasah Bertaraf Internasional Amanatul Ummah Mojokerto" who experienced menstrual pain as many as 126 people. The sampling technique was purposive sampling with the calculation of the Slovin formula, obtained as many as 56 students. The research instrument used an observation sheet measuring the Numeric Rating Scale. Data analysis using independent $t$-test.

Results: The results of the study showed differences in menstrual decline between the experimental group and the control group with $p=0.001(p<0.05)$.

The average rate of decline in the experimental group was 3.79 and the control group was 2.00. This stated that acupressure at Hegu point can reduce menstruation in class XI students of "Madrasah Bertaraf Internasional Amanatul Ummah Mojokerto".

Conclusion: Acupressure at Hegu point can be done to reduce menstrual pain.

Keywords: Acupressure, Hegu point, menstrual pain.

\section{PENDAHULUAN}

Menstruasi merupakan tanda pubertas dari seorang wanita dan menjadi sebuah rutinitas pada wanita yang masih dalam masa subur. Siklus ini kadangkadang menyebabkan ketidaknyamanan karena sering menimbulkan nyeri atau rasa tidak nyaman di perut. Rasa nyeri merupakan masalah kesehatan yang dapat memberikan dampak signifikan pada kualitas kehidupan wanita. Salah satu gangguan saat menstruasi adalah disminore. Dismenorhea merupakan nyeri perut bagian bawah yang terjadi saat menstruasi, terkadang rasa nyeri tersebut meluas hingga ke pinggang, punggung bagian bawah dan paha. Nyeri ini dapat memaksa penderita untuk istirahat dan meninggalkan pekerjaan atau cara hidupnya sehari-hari, untuk beberapa jam atau beberapa hari. (Wilson dalam Kostania, 2016) Gangguan ini ada 2 bentuk, yaitu disminore primer dan sekunder. Disminore primer yaitu nyeri menstruasi yang terjadi tanpa terdapat kelainan anantomis alat kelamin, sedangkan disminore sekunder adalah nyeri yang berhubungan dengan kelainan anatomis yang jelas (Manuaba, 2009).

Disminore merupakan masalah kandungan yang sering dialami wanita disegala usia dengan rata- rata lebih dari 50\%. Angka prevalensinya di Ethiopia sebanyakk 77,6\%, di Thailand sebanyak 84,2 \% dan di Indonesia sebanyak 64,25\% (Gebeyehu et al, 2017; Santoso, 2008). Menurut Gebeyahu et al (2017), disminore apabila tidak dievaluasi atau ditangani akan mempengaruhi penurunan prestasi akademik 51,4\%, aktivitas terbatas selama menstruasi $40,9 \%$, absen dari kelas $31,1 \%$, penurunan konsentrasi $43,3 \%$, penurunan nafsu 
makan dan mengubah pola tidur $42,7 \%$ dan penarikan masyarakat atau sosial 63\% sehingga diperlukan cara untuk mengatasi disminore tersebut.

Ada beberapa cara untuk mengatasi disminore baik secara farmakologis ataupun nonfarmakologis. Terapi farmakologi untuk mengurangi disminore meliputi analgesik, obat - obatan antiradang bukan steroid (nonsteroid antiinflammatory drugs) [NSAID]), pil kontrasepsi oral, diuretik. Selain itu, terapi nonfarmakologi yang bisa mengurangi disminore antara lain akupunkture, herbalisme, massage, aromaterapi, hipnoterapi, yoga, akupressure, latihan relaksasi, diet dan tidur cukup (Lowdermilk et al, 2013; Reeder, 2014). Salah satu terapi nonfarmakologis yang bisa diterapkan adalah akupresure.

Berdasarkan studi pendahuluan yang telah dilakukan oleh peneliti yang dilakukan peneliti terhadap 20 santriwati, terdapat $80 \%$ santriwati mengalami nyeri menstruasi dan 55\% diantaranya terjadi pada hari pertama menstruasi dan lebih dari setengahnya memilih tidur untuk mengurangi nyeri menstruasi. Dampaknya antara lain malas melakukan aktivitas, tidak fokus belajar, pusing, lelah emosi lebih sensitif dan merasa lemas. Dari penanganan yang dipilih santriwati, terbukti bahwa santriwati belum mengetahui tentang akupressure dapat mengurangi nyeri menstruasi sehingga peneliti tertarik untuk mengetahui apakah ada pengaruh akupressure titik Hegu terhadap nyeri menstruasi pada santriwati kelas XI Madrasah Bertaraf Internasional Amanatul Ummah Mojokerto.

\section{METODE PENELITIAN}

Penelitian ini merupakan penelitian observasional dengan jenis quasy eksperimental desain dengan rancangan non equivalent control group, yaitu dengan melihat nilai rata- rata penurunan tingkat nyeri pada kelompok kontrol dan eksperimen. Penelitian ini dilakukan di Madrasah Bertaraf Internasional Amanatul Ummah Mojokerto pada bulan Januari s.d. Mei 2018. Populasi aktualnya yaitu santriwati kelas XI Madrasah Bertaraf Internasional Amanatul Ummah Mojokerto yang mengalami nyeri menstruasi sebanyak 126 orang. Teknik pengambilan sample adalah purposive sample dengan perhitungan rumus Slovin. Didapatkan sebanyak 56 santriwati yang dibagi menjadi 2 kelompok, yaitu kelompok eksperimen diberikan perlakuan akupresure titik Hegu pada saat menstruasi dan kelompok kontrol dianjurkan untuk relaksasi. Instrumen yang digunakan adalah lembar observasi tingkat nyeri yang diisi sebelum dilakukan akupresure (pretest) dan 3 jam setelah dilakukan akupresure (posttest) menggunakan Numeric Rating Scale, dan panduan pijat akupresure titik Hegu. Analisis data yang digunakan adalah statistik parametrik dengan pengujian independent t-test yang sebelumnya dilakukan uji normalitas data. 
1. Karakteristik Responden

Tabel 1. Karakteristik Responden berdasarkan Umur dan Status Gizi

\begin{tabular}{|c|c|c|c|c|c|c|c|}
\hline \multirow{2}{*}{\multicolumn{2}{|c|}{ Karakteristik }} & \multicolumn{2}{|c|}{ Eksperimen } & \multicolumn{2}{|c|}{ Kontrol } & \multicolumn{2}{|c|}{ Total } \\
\hline & & $\mathbf{n}$ & $(\%)$ & $\mathbf{n}$ & $(\%)$ & $\mathbf{n}$ & $(\%)$ \\
\hline \multirow[t]{6}{*}{1} & $\begin{array}{l}\begin{array}{l}\text { Umur } \\
\text { (Tahun) }\end{array}\end{array}$ & & & & & & \\
\hline & 15 & 6 & 21 & 11 & 39 & 17 & 30 \\
\hline & 16 & 15 & 54 & 17 & 61 & 32 & 57 \\
\hline & 17 & 5 & 18 & 0 & 0 & 5 & 9 \\
\hline & 18 & 2 & 7 & 0 & 0 & 2 & 4 \\
\hline & Jumlah & 28 & 100 & 28 & 100 & 56 & 100 \\
\hline \multirow[t]{7}{*}{2} & $\begin{array}{l}\text { Status Gizi } \\
\text { (Indeks Masa Tubuh } \\
\text { dalam kg/m²) }\end{array}$ & & & & & & \\
\hline & Kurang $(<18,5)$ & 4 & 14 & 4 & 14 & 8 & 14 \\
\hline & Normal $(18,5-22,9)$ & 18 & 64 & 20 & 71 & 38 & 68 \\
\hline & $\begin{array}{l}\text { Gizi Lebih }(<23- \\
24,9)\end{array}$ & 3 & 11 & 1 & 4 & 4 & 7 \\
\hline & Obesitas I $(25,0-29,9)$ & 2 & 7 & 3 & 11 & 5 & 9 \\
\hline & Obesitas II (>30) & 1 & 4 & 0 & 0 & 1 & 2 \\
\hline & Jumlah & 28 & 100 & 28 & 100 & 56 & 100 \\
\hline \multirow[t]{5}{*}{3} & $\begin{array}{l}\text { Menarche } \\
\text { (Tahun) }\end{array}$ & & & & & & \\
\hline & 11 & 8 & 29 & 7 & 25 & 15 & 27 \\
\hline & 12 & 16 & 57 & 11 & 39 & 27 & 48 \\
\hline & 13 & 4 & 14 & 10 & 36 & 14 & 25 \\
\hline & Jumlah & 28 & 100 & 28 & 100 & 56 & 100 \\
\hline
\end{tabular}

Sumber: data primer, 2018

Pada tabel 1., dapat dilihat distribusi responden berdasarkan umur dan status gizi pada setiap kelompok. Umur responden pada kedua kelompok mayoritas berusia 16 tahun, pada kelompok eksperimen sebanyak (54\%), sedangkan pada kelompok kontrol sebanyak (61\%). Untuk status gizi pada kelompok ekperimen mayoritas memiliki Indeks Masa Tubuh (IMT) normal (18,5 - 22,9 sebanyak (64\%). Begitu juga dengan kelompok kontrol, mayoritas memiliki IMT normal (18,5 - 22,9 sebanyak (71\%). Pada kelompok eksperimen dan kontrol, mayoritas mengalami menarche pada umur 12 tahun, kelompok ekperimen (57\%), dan kelompok kontrol (39\%).

2. Deskripsi tingkat nyeri pada kelompok eksperimen sebelum dan sesudah diberikan akupresure

Tabel 2. Diskripsi tingkat nyeri sebelum dan sesudah dilakukan akupresure pada kelompok eksperimen

\begin{tabular}{lrrr}
\hline \multicolumn{1}{c}{ Kelompok Eksperimen } & Min & Mean & Max \\
\hline Pre Test & 3 & 6,50 & 10 \\
Post Test & 0 & 2,67 & 6 \\
\hline
\end{tabular}


Pada tabel 2. dapat dilihat deskripsi tingkat nyeri sebelum dan sesudah dilakukan akupresure pada titik Hegu pada kelompok eksperimen. Pengukuran sebelum perlakuan (pre test), nilai minimum (skor terendah) sebesar 3 dan nilai maximum (skor terbesar) sebesar 10. Angka ini menunjukkan nyeri yang dirasakan responden pada kelompok eksperimen sebelum diberikan perlakuan bervariasi dari ringan hingga sangat berat. Nilai mean (rata-rata) sebesar 6,50 yang berarti rata-rata responden memiliki nyeri menstruasi dengan kategori sedang.

Pengukuran setelah perlakuan (post test), nilai minimum (skor terendah) sebesar 0 dan nilai maximum (skor terbesar) sebesar 6. Angka ini menunjukkan bahwa nyeri responden pada kelompok eksperimen setelah diberikan perlakuan bervariasi dari tidak nyeri hingga nyeri sedang. Nilai mean (rata- rata) sebesar 2,67, yang berarti rata-rata responden memiliki nyeri menstruasi dengan kategori ringan.

3. Deskripsi tingkat nyeri pada kelompok kontrol sebelum dan sesudah diberikan akupresure

Tabel 3. Diskripsi tingkat nyeri sebelum dan sesudah dilakukan akupresure pada kelompok kontrol

\begin{tabular}{lrrr}
\hline Kelompok Kontrol & Min & Mean & Max \\
\hline Pre Test & 1 & 5,42 & 10 \\
Post Test & 0 & 3,53 & 8 \\
\hline
\end{tabular}

Pada tabel 3. dapat dilihat deskripsi tingkat nyeri sebelum dan sesudah perlakuan pada kelompok kontrol. Kelompok kontrol diberikan perlakuan berupa relaksasi nafas dalam. Hasil pengukuran sebelum diberikan perlakuan (pre test), nilai minimum (skor terendah) sebesar 1 dan nilai maximum (skor terbesar) sebesar 10. Angka ini menunjukkan responden kelompok kontrol memiliki respon nyeri yang bervariasi, dari ringan hingga sangat berat. Nilai mean (rata-rata) sebesar 5,42 yang berarti rata-rata responden memiliki nyeri menstruasi dengan kategori sedang.

Hasil pengukuran setelah diberikan perlakuan (post test), nilai minimum (skor terendah) sebesar 0 dan nilai maximum (skor terbesar) sebesar 8. Angka ini menunjukkan respon nyeri pada responden kelompok kontrol bervariasi dari tidak nyeri hingga nyeri berat. Nilai mean (rata- rata) sebesar 3,53, yang berarti rata-rata responden memiliki nyeri menstruasi dengan kategori ringan.

4. Analisis pengaruh akupresure titik Hegu terhadap nyeri menstruasi

Tabel 4. Rata- rata penurunan tingkat nyeri menstruasi terhadap kelompok yang diberikan Akupresure titik Hegu dan tidak diberikan Akupresure

\begin{tabular}{lccc}
\hline Kelompok & $\begin{array}{c}\text { Rata-Rata Penurunan } \\
\text { Tingkat Nyeri }\end{array}$ & t-hitung & $\begin{array}{c}\text { Sig (2 } \\
\text { tailed) }\end{array}$ \\
\hline Eksperimen & 3,79 & 5,680 & 0,001 \\
Kontrol & 2,00 & & \\
\hline
\end{tabular}


Pada tabel 4 menunjukkan bahwa rata-rata penurunan tingkat nyeri menstruasi pada kelompok yang dilakukan akupresure pada titik Hegu sebesar 3,79, sedangkan untuk kelompok yang tidak dilakukan akupresure sebesar 2,00. Independent $t$-test digunakan untuk membandingkan rata-rata penurunan tingkat nyeri pada kelompok eksperimen dan kelompok kontrol. Pada tabel 4.4 didapat bahwa t-hitung lebih besar dari t- tabel $(5,680>2,004)$ dan nilai $\mathrm{p}$ lebih kecil dari $\alpha(0,001<0,05)$. Hal ini menunjukkan bahwa hipotesis diterima, yang artinya ada pengaruh Akupresurepada titik Hegu terhadap nyeri menstruasi.

Hasil penelitian tentang pengaruh akupresure titik Hegu terhadap nyeri menstruasi pada santriwati kelas XI Madrasah Bertaraf Internasional Amanatul Ummah Mojokerto adalah terdapat pengaruh akupresure pada titik Hegu terhadap nyeri menstruasi. Hal ini dibuktikan dengan hasil uji independent t-test yang menunjukkan nilai $\mathrm{p}$ lebih kecil dari $\alpha(0,001<0,05)$ dan nilai t-hitung lebih besar dari t-tabel $(5,680>2,004)$. Hasil ini sejalan dengan penelitian Julianti (2014) yang didapatkan hasil bahwa pemberian terapi akupresure Hegu (LI4) efektif menurunkan intensitas nyeri sebesar 0,615 poin dan $\mathrm{P}(0,007)<(\alpha$ $0,05)$

Hasil penelitian pada kelompok eksperimen menunjukkan bahwa responden mengalami penurunan tingkat nyeri dari kategori sedang ke ringan setelah diberikan akupresure titik Hegu. Sebelum diberikan perlakuan akupresure pada titik Hegu mempunyai nilai minimal 3, rata-rata 6,50 dan maksimal 10. Hal ini menunjukkan bahwa rata-rata respoden berada dalam tingkat kategori sedang. Menurut Manuaba (2007) nyeri sedang masih dapat melakukan aktivitas dan memerlukan obat penghilang nyeri. Setelah diberikan akupresure nilai minimal 0 , rata- rata 2,67 dan maksimal 6. Hal ini menunjukkan bahwa setelah dilakukan akupresure rata-rata responden berada dalam kategori ringan. Menurut Manuaba (2007) nyeri ringan tidak mengganggu dan masih dapat melakukan aktivitas.

Pada kelompok kontrol, setelah diberikan perlakuan berupa relaksasi nafas dalam mempunyai nilai minimal 1 , rata-rata 5,42 dan maksimal 10 . Hal ini menunjukkan bahwa rata-rata respoden berada dalam tingkat kategori sedang. Menurut Manuaba (2007) nyeri sedang masih dapat melakukan aktivitas dan memerlukan obat penghilang nyeri. Setelah diberikan akupresure nilai minimal 0 , rata- rata 3,53 dan maksimal 8 . Hal ini menunjukkan bahwa setelah dilakukan akupresure rata-rata responden berada dalam kategori ringan. Menurut Manuaba (2007) nyeri ringan tidak mengganggu dan masih dapat melakukan aktivitas. Hasil penelitian pada kelompok kontrol menunjukkan bahwa responden mengalami penurunan tingkat nyeri dari kategori sedang ke ringan meskipun tanpa diberikan akupresure titik Hegu.

Penurunan nyeri menstruasi pada santriwati setelah 3 jam dilakukan akupresure lebih besar daripada santriwati yang tidak diberikan akupresure $(3,79$ $>2,00$ ). Menurut Potter \& Perry (2010), penurunan tingkat nyeri menstruasi sesuai dengan teori gate control. Jika ada perpindahan implus yang besar seperti rangsangan kulit, sentuhan, getaran, panas dan dingin dan sentuhan halus maka implus akan menghalangi di area substansi gelatinosa sehingga sensasi yang dibawa oleh serabut- serabut kecil akan direduksi sehingga tidak dapat 
merasakan nyeri, kondisi ini menyebabkan gate tertutup.

Menurut Alamsyah (2010), titik Hegu merupakan titik yuan (titik sentral) dari meredian usus besar (Large Intestine Meredian). Artinya titik ini merupakan tempat organ usus besar terpencar ke sepanjang titik merediannya. Jika ada gangguan atau hambatan di titik meredian usus besar, titik ini merupakan sentralnya. Titik ini berperan sebagai penenang dan antispasmodic yang sangat kuat sehingga digunakan dalam kondisi yang menyakitkan baik pada meredian/organ, khususnya lambung, usus dan uterus (hal ini dapat digunakan untuk penurunan nyeri menstruasi). Titik ini juga memiliki pengaruh yang kuat pada pikiran dan tepat digunakan untuk menenangkan pikiran dan menghilangkan kecemasan.

Pemberian terapi akupresure pada titik Hegu bukan merupakan satu-satunya faktor yang dapat mengurangi nyeri menstruasi pada remaja. Ada bebrapa faktor lain yang ikut berpengaruh, diantaranya adalah usia remaja, status gizi dan usia saat menarche.

Dari 56 responden, didapatkan bahwa paling banyak responden berusia 16 tahun (57\%). Menurut Ammar (2016), rentang usia nyeri menstruasi pada usia 15-25 tahun. Perempuan pada usia 25 tahun mengalami peningkatan rasa nyeri dan sampai usia mencapai 30-35 tahun nyeri akan berkurang (Reeder\&Koniak,2011). Bertambahnya umur menjadi penyebab nyeri menstruasi menghilang karena adanya kemunduran syaraf rahim akibat penuaan. Menurut Suliawati (2013) ada hubungan umur dengan kejadian nyeri menstruasi pada wanita usia subur.

Sebagian besar responden status gizinya normal (68\%). Status gizi merupakan keadaan kesehatan tubuh seseorang yang diakibatkan oleh konsumsi, penyerapan, dan penggunaan zat gizi makanan (Jones,2008). Menurut Kuswandi (2013) status gizi bukan satu-satunya faktor yang mempengaruhi dismenore. Terdapat faktor lain yang dapat mempengaruhi, antara lain faktor fisik dan psikis seperti stress dan pengaruh hormon prostaglandin dan progesteron. Hal ini tidak sejalan dengan teori menurut Hellmann et al (2013), pada penderita obesitas respon imun bawaan berubah sehingga bisa meningkatkan asam lemah jenuh pada penderita obesitas sehingga mengubah resolusi peradangan dengan merangsang produksi prostaglandin dan mengurangi fagositosis makrofag. Jumlah prostaglandin meningkat dalam inflamasi sehingga pada penderita obesitas terdapat peningkatan kadar prostaglandin. Prostaglandin menyebabkan kontraksi uterus meningkat sehingga menyebabkan nyeri menstruasi. Dan hasil penelitian Sophia (2013) yang menyatakan bahwa status gizi rendah (underweight) memiliki kemungkinan resiko 1,2 kali lebih besar dan status gizi lebih (overweight) memiliki kemungkinan resiko 1,1 kali lebih besar mengalami dismenore dibandingkan dengan siswi dengan status gizi normal.

Responden yang mengalami nyeri menstruasi paling banyak mengalami menarche pada usia 12 tahun sebanyak 27 orang (48\%). Menarche merupakan waktu pertama kalinya menstruasi. Usia menarche yang ideal adalah 12 sampai 14 tahun, namun pada beberapa kasus dapat terjadi pada usia $\leq 12$ tahun. Hasil penelitian Beddu (2015) menyatakan bahwa ada hubungan antara usia menarche 
dengan nyeri menstruasi dengan hasil $\mathrm{p}=0,006$ dan penelitian yang lain yang mengatakan bahwa usia dan menarche merupakan faktor yang mempengaruhi dengan nyeri menstruasi dengan hasil $\mathrm{p}=0,013$ (Mukhoirotin, 2018). Menarche lebih awal memiliki kemungkinan 1,6 kali lebih besar mengalami nyeri menstruasi karena alat reproduksi belum berfungsi dengan secara optimal dan belum siap mengalami perubahan dan masih terjadi penyempitan leher rahim sehingga timbul nyeri saat menstruasi. Hasil penelitian ini sama dengan teori yang mengatakan bahwa usia menarche yang cepat menjadi faktor risiko terjadinya dismenorea primer (Nurwana, 2016).

Meskipun ada beberapa faktor lain yang berpengaruh terhadap nyeri menstruasi, namun pemberian terapi akupresure pada titik Hegu cukup efektif dalam mengatasi nyeri menstruasi. Akupresure pada titik Hegu baik yang single point atau yang kombinasi dapat mengurangi nyeri menstruasi secara efektif. Akupresure ini efektif, murah, dan aman untuk remaja yang mengalami nyeri menstruasi. Disamping dapat dilakukan oleh tenaga kesehatan, dapat juga dilakukan sendiri (Chen \& Chen,2010).

Pemberian akupresure efektif mengurangi nyeri menstruasi, karena akupresure berperan sebagai analgesik. Hal ini karena akupresure dapat meningkatkan hormon endorpin, yaitu hormon yang mampu menghadirkan rasa rileks pada tubuh secara alami dan memblok reseptor nyeri pada otak. Endorpin mengontrol aktivitas kelenjar endokrin. Selain itu endorpin dapat mempengaruhi daerah pengindra nyeri di otak dengan cara serupa dengan obat opiat yaitu morpin. Pelepasan endorpin dikontrol oleh sistem syaraf. Jaringan syaraf sensitif terhadap nyeri dan rangsangan dari luar dan jika dipicu dengan menggunakan akupresure akan memerintahkan sistem endokrin untuk melepasakan sejumlah endorpin sesuai kebutuhan tubuh (Aprilia, 2010).

Nyeri menstruasi berupa dysmenorrhea primer merupakan salah satu masalah pada kesehatan reproduksi yang harus ditangani dengan tepat. Penanganan yang tepat dengan memberikan perawatan khusus, juga dengan memberikan pengobatan yang efektif dan tepat waktu. Sebaiknya tenaga kesehatan tidak memberikan terapi konvensional yaitu dengan pemberian obat kimia sebagai pilihan utama ketika berhadapan dengan dismenore primer, namun lebih memilih pengobatan non konvensional, yaitu dapat berupa obatobatan berbahan dasar herbal maupun terapi komplementer yang lain (Kostania, 2016).

Pelaksanaan layanan terapi komplementer oleh bidan masih sangat minim. Kostania (2015) menyatakan bahwa pelayanan terapi komplementer baru dilaksanakan oleh $(14,4 \%)$ bidan, dan mayoritas responden $(86,2 \%)$ belum pernah mengikuti seminar dan/ pelatihan tentang terapi komplementer. Dengan hasil penelitian ini diharapkan dapat menjadi khasanah keilmuan untuk meningkatkan penggunaan terapi komplementer dalam layanan kebidanan khususnya penanganan nyeri menstruasi. 


\section{SIMPULAN DAN SARAN}

\section{Simpulan}

Tingkat nyeri menstruasi pada kelompok eksperimen setelah dilakukan akupresure pada titik Hegu mengalami penurunan dari tingkatan sedang menjadi ringan (mean 6,50 menjadi 2,67). Sedangkan pada kelompok kontrol yaitu yang tidak diberikan akupresure pada titik Hegu mengalami penururan dari tingkat sedang ke ringan (mean 5,42 menjadi 3,53). Akupresure pada titik Hegu dapat dilakukan untuk mengurangi nyeri menstruasi, dengan nilai $p=0,001 \quad(p<0,05)$ atau t-hitung $>$ t-tabel $(5,680>2,004)$. Dapat disimpulkan bahwa akupresure pada titik Hegu berpengaruh dalam penurunan nyeri menstruasi, sehingga aktivitas selama menstruasi tidak terganggu, konsentrasi tetap dan santriwati tidak absen pelajaran. Akupresure pada titik Hegu dapat menjadi teknik non farmakologi untuk mengatasi nyeri menstruasi pada remaja.

\section{Saran}

Diharapakan bidan mampu memberikan terapi akupresure dalam pelayanan kebidanan khususnya pada remaja yang mengalami nyeri menstruasi dengan cara memberikan intervensi secara langsung atau memberikan pendidikan kesehatan kepada remaja, guru, serta orang tua. Masyarakat khususnya remaja dapat menerapkan terapi non farmakologis, salah satunya akupresure terhadap nyeri menstruasi guna mengurangi ketergantungan terhadap obat-obatan sejak dini.

\section{DAFTAR PUSTAKA}

Alamsyah, I. (2010) Cara Lebih Mudah Menemukan Titik Terapi Acupoint. Depok: Asma Nadia.

Ammar Ulya Rohima (2016), Faktor Risiko Dismenore Primer Pada Wanita Usia Subur di Kelurahan Ploso Kecamatan Tambaksari Surabaya, 4 Januari 2016, pp. 37-49. doi: 10.20473/jbe.v4i1.37-49

Aprilia, Y. (2010). Hipnostetri : Rileks, Nyaman, dan Aman Saat Hamil dan Melahirkan. Jakarta : Gagas Media.

Beddu, S., Mukarramah, S. and Lestahulu, V. (2015) 'Hubungan Status Gizi Dan Usia Menarche Dengan Dismenore Primer Pada Remaja Putri', The Southeast Asian Journal of Midwifery, 1(1), pp. 16-21.

Chen, H. M. and Chen, C. H. (2010) 'Effects of acupressure on menstrual distress in adolescent girls: A comparison between HeguSanyinjiaoMatchedPointsandHegu, Zusanli single point', Journal of ClinicalNursing,19(7-8),pp.998-1007. doi: 10.1111/j.13652702.2009.02872.x

Gebeyehu, M. B. et al. (2017) 'Prevalence, Impact, and Management Practice of Dysmenorrhea among University of Gondar Students, Northwestern Ethiopia: A Cross-Sectional Study', International Journalof Reproductive Medicine, 2017, pp.1-8. doi: $10.1155 / 2017 / 3208276$. 
Julianti and Hasanah, O. (2014) 'Efektifitas akupresur terhadap dismenore pada remaja putri', Jom Psik, 1(2), p. 2

Kostania, G. (2015). Pelaksanaan Pelayanan Kebidanan Komplementer Pada Bidan Praktek Mandiri di kabupaten Klaten. Gaster: Jurnal Kesehatan, 12(1), 46-72.

Kostania, G., \& Kurniawati, A. (2016).Perbedaan Efektivitas Ekstrak Jahe dengan Ekstrak Kunyit dalam Mengurangi Nyeri Dismenorhea Primer pada Mahasiswi di Asrama Jurusan Kebidanan Poltekkes Surakarta. Interest: Jurnal Ilmu Kesehatan, 5(2).

Lowdermilk, D. L., Perry, S. E. and Cashion, K. (2013) Keperawatan maternitas, Nursing.Singapura; Salemba Medika.

Manuaba, I. B. G. (2009). Memahami Kesehatan Reproduksi Wanita (2 ed.). Jakarta: EGC.

Potter \& Perry. (2010). Fundamental of Nursing edisi 7. Jakarta : Salemba medika.

Reeder,Sharon J. (2014) maternity nursing; family, newborn and women's health care. 18th edn. Jakarta: EGC. 